1 Department of Thoracic Medicine, Wexham Park Hospital, Frimley Health Foundation Trust, Slough, SL2 4HL, UK

2 Oxford Centre for Respiratory Medicine, Churchill Hospital, Oxford University Hospitals NHS Foundation Trust, Headington, OX3 7LE, UK

3 University of Oxford Department of Physiology Anatomy and Genetics, Oxford, UK

4 Department of Intensive Care Medicine, John Radcliffe Hospital, Oxford University Hospitals NHS Foundation Trust, Headington, OX3 9DU, UK

5 Clarendon Lodge Medical Practice, Leamington Spa CV32 5SS, UK

Correspondence to: T W Nicholson Thomas.nicholson2@nhs.net Cite this as: BMJ 2020;369:m2446 http://dx.doi.org/10.1136/bmi.m2446 Published: 30 June 2020

\title{
Respiratory failure and non-invasive respiratory support during the covid-19 pandemic: an update for re-deployed hospital doctors and primary care physicians
}

\author{
Thomas W Nicholson, ${ }^{1}$ Nick P Talbot, ${ }^{2,3}$ Annabel Nickol, ${ }^{2}$ Andrew J Chadwick, ${ }^{4}$ Oliver Lawton ${ }^{5}$
}

\section{What you need to know}

- Most patients who become seriously unwell with covid-19 do so primarily due to acute type 1 respiratory failure and benefit from early recognition of respiratory deterioration and appropriate escalation in respiratory support

- Respiratory deterioration can be identified by an increasing respiratory rate, an inability to talk in full sentences, the use of accessory muscles of breathing, decreasing oxygen levels in the blood, and an increased requirement for supplementary oxygen

- All patients with covid-19 admitted to hospital and many of those in the community should have a ceiling of care established at the earliest opportunity

In response to the covid-19 pandemic, many health systems attempted to rapidly reorganise their healthcare workforce in the first half of 2020, including redeployment of doctors from primary care and non-frontline specialties to acute care wards. ${ }^{1}$ Preparedness for potential future redeployment remains essential given the risk of further waves of covid-19 as society negotiates repeated cycles of lockdown and reopening.

Most people who become seriously unwell with covid-19 have an acute respiratory illness, ${ }^{2-4}$ and about $14 \%$ will require non-invasive respiratory support. ${ }^{2}$ In addition to shifting into acute care settings in the short term, primary care clinicians will also be caring for patients (or their loved ones) recovering from potentially traumatic experiences of respiratory illness. This article updates primary care and non-respiratory or intensivist specialist doctors on the recognition and non-invasive management of acute respiratory failure and will aid general practitioners in the subsequent outpatient support of patients during their recovery.

\section{Case scenario}

A 50 year old man has been self isolating for eight days with fever and a cough. He was brought to the emergency department by ambulance after becoming increasingly breathless over the past two days.

He can speak complete sentences but has an elevated respiratory rate of 24 breaths per minute (normal range 12-20). His peripheral oxygen saturation ( $\mathrm{SpO} 2$ ) was $72 \%$ breathing room air when the paramedics arrived, and $90 \%$ on oxygen therapy $(4 \mathrm{~L} / \mathrm{min})$ via nasal cannula. Cardiovascular observations are normal and he is apyrexial.

\section{Defining and classifying respiratory failure}

The respiratory system moves oxygen from the external environment into the bloodstream while removing carbon dioxide. This requires adequate ventilation (the movement of gas into and out of the lungs) and gas exchange (the movement of oxygen and carbon dioxide between the lung and the blood). Respiratory failure refers to the situation in which one or both of these processes fails. This may lead to low oxygen levels (hypoxia) with or without high carbon dioxide levels (hypercapnia). Both hypoxia and hypercapnia act as stimuli to breathe, with hypercapnia the more powerful in most situations. They lead to breathlessness that manifests in patients as air hunger, chest tightness, or an inability to breathe deeply (see infographic).

Type 1 respiratory failure $\left(T_{1} R F\right)$ is primarily a problem of gas exchange resulting in hypoxia without hypercapnia.

Type 2 respiratory failure $(T 2 R F)$ occurs when there is reduced movement of air in and out of the lungs (hypoventilation), with or without interrupted gas transfer, leading to hypercapnia and associated secondary hypoxia (table 1). 


\begin{tabular}{|c|c|c|}
\hline & Type 1 respiratory failure (T1RF) & Type 2 respiratory failure (T2RF) \\
\hline Oxygen (arterial P02) & Low & Low \\
\hline Carbon dioxide (arterial PCO2) & Normal or low (८6 kPa) & Elevated (>6 kPa) \\
\hline Minute ventilation & $\begin{array}{l}\text { Normally high as patient will typically hyperventilate in response to the } \\
\text { hypoxia }\end{array}$ & Low \\
\hline Pathophysiology & $\begin{array}{l}\text { - Caused by a problem with transfer of gas from the lung into the blood } \\
\text { - May be due to a problem with diffusion of gas from alveolus into blood, } \\
\text { but more often due to poor matching of gas and blood flow ("VQ matching") } \\
\text { across the lung } \\
\text { - Both these problems have a much greater impact on oxygen (primarily } \\
\text { due to its low blood solubility) than carbon dioxide. The PCO2 is therefore } \\
\text { normal (or, more usually, low due to hyperventilation and increased "blowing } \\
\text { off" of carbon dioxide from the lung) }\end{array}$ & $\begin{array}{l}\text { - Primarily due to a failure of ventilation (failure to move enough gas into and out } \\
\text { of the lungs), leading to reduced oxygen intake and reduced removal of CO2 from } \\
\text { the lungs } \\
\text { - Impairment of ventilation may be due to reduced respiratory drive, increased } \\
\text { airway resistance, reduced compliance (increased "stiffness") of the respiratory } \\
\text { system, or respiratory muscle weakness } \\
\text { • Underlying gas exchange may be normal when there is respiratory muscle } \\
\text { weakness with healthy lungs, or impaired when there is lung disease with a } \\
\text { "mixed" picture T1RF and T2RF (such as severe COPD) }\end{array}$ \\
\hline Examples & $\begin{array}{l}\text { - Pneumonia-Alveoli are filled with inflammatory exudate and/or sputum, } \\
\text { impairing gas exchange } \\
\text { - Heart failure-Alveoli fill with fluid (pulmonary oedema), impairing gas } \\
\text { exchange } \\
\text { - Asthma-VQ matching is impaired due to small airway closure and mucus } \\
\text { plugging (type } 2 \text { respiratory failure is seen only in very severe asthma, } \\
\text { typically when the patient is too tired to hyperventilate) } \\
\text { - Pulmonary embolism-Blood flow is blocked to one or more regions of } \\
\text { lung, leading to poor VQ matching across the lung overall } \\
\text { - High altitude pulmonary oedema-Reduced FiO2 leads to uneven } \\
\text { pulmonary vasoconstriction and leak of inflammatory exudate into the } \\
\text { alveolar space }\end{array}$ & $\begin{array}{l}\text { - Opiate toxicity-Opiates reduce respiratory drive due to effects in the central } \\
\text { nervous system } \\
\text { - latrogenic over-oxygenation-Hypoxic ventilatory drive is abolished in a patient } \\
\text { with metabolic compensation for hypercapnia (raised base excess and } \\
\text { bicarbonate) and relaxation of hypoxic vasoconstriction allows perfusion of poorly } \\
\text { ventilated lung units. } \\
\text { - Neuromuscular disease-Such as motor neurone disease, muscular dystrophy. } \\
\text { Often present initially with overnight hypercapnia } \\
\text { - Reduced chest wall compliance-Such as obesity, kyphoscoliosis } \\
\text { - Increased airway resistance-Such as COPD } \\
\text { - Severe impairment of gas exchange-Such as exacerbation of COPD, with both } \\
\text { poor gas exchange and low minute ventilation }\end{array}$ \\
\hline
\end{tabular}

The basis for the difference between T1RF and T2RF is that oxygen levels are sensitive to problems with either gas exchange or ventilation. In contrast, because of the gas' greater solubility in blood than oxygen, carbon dioxide levels are not as severely affected by problems with gas exchange but are equally sensitive to impaired ventilation.

\section{Respiratory failure due to covid-19}

Covid-19 is caused by the severe acute respiratory syndrome coronavirus 2 (SARS-CoV-2), which primarily targets the respiratory tract, causing widespread inflammation in the lungs in severe cases. Approximately $14 \%$ of all people with covid-19 develop severe respiratory disease with $\mathrm{T} 1 \mathrm{RF}$, and a further $5 \%$ will become critically unwell, ${ }^{2}$ many of whom will require intensive care. ${ }^{56}$
In keeping with other reports, ${ }^{78}$ there is a subset of patients with covid-19 who do not require intubation but who have severe hypoxaemia that is refractory to simple oxygen therapy and who require non-invasive respiratory support. Despite extensive inflammatory changes in the lungs, which may be evident radiologically (fig 1), ventilation seems to be less severely impaired than gas exchange resulting in (often) severe hypoxia without hypercapnia (T1RF). Indeed, patients often have no difficulty moving large volumes of air in and out of the lungs; hence the lack of hypercapnia (T2RF) in most patients and the observation that dyspnoea may be absent or disproportionately mild relative to the severity of disease..$^{8}$ 

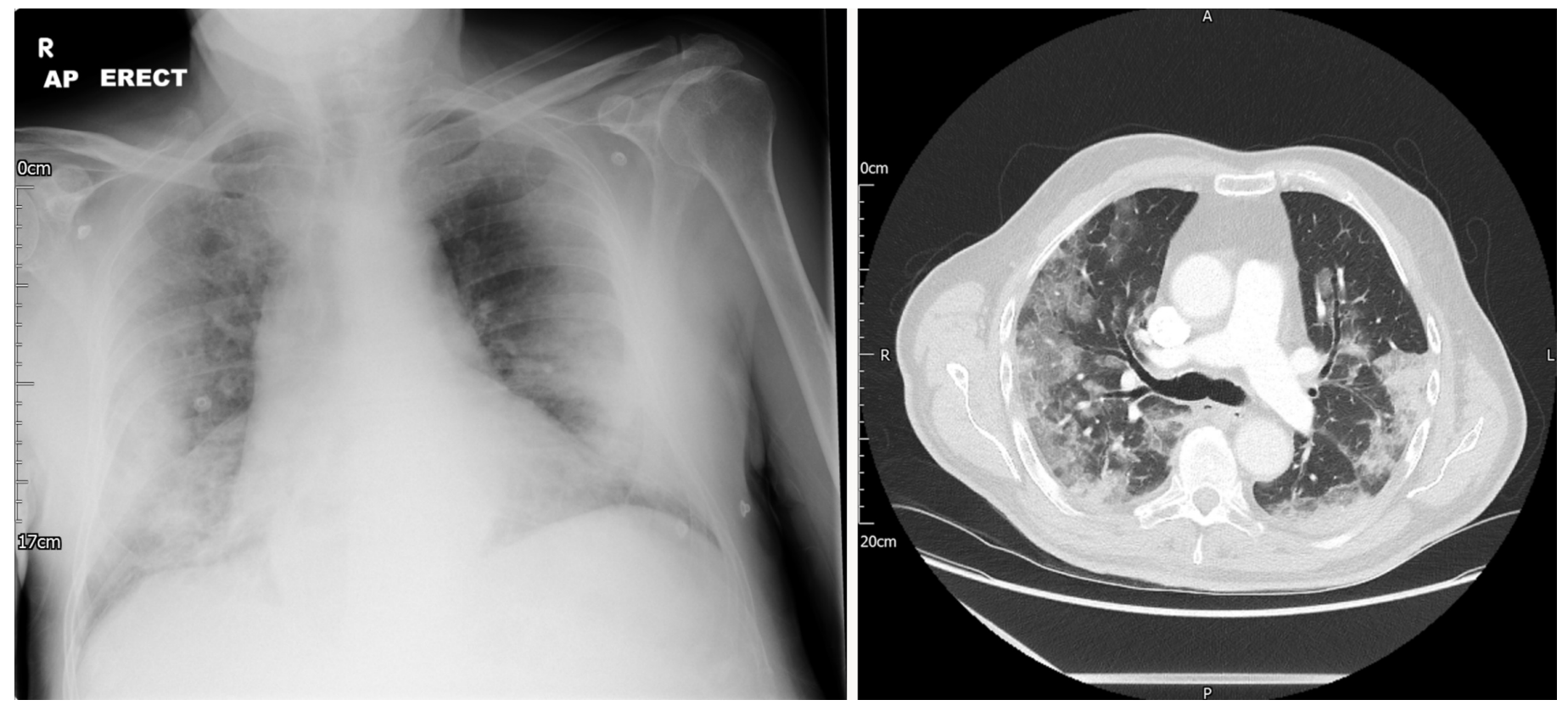

Fig 1 | Chest radiograph (left) and axial thoracic computed tomography (right) showing multifocal ground glass with early consolidation in patients with severe covid-19

Some authors have suggested that there are different stages of severe covid-19. In the early phase, hypoxia may be driven primarily by damage or dysregulation to the pulmonary blood vessels, ${ }^{7-10}$ leading to impaired transfer of oxygen from the lungs to the bloodstream. Some of these patients will go on to recover over a period of days to weeks. If the patient continues to deteriorate, however, the clinical picture may become more typical of acute respiratory distress syndrome (ARDS) from any aetiology, with diffuse alveolar damage and inflammatory oedema that necessitates intubation and mechanical ventilation. ${ }^{7911}$

\section{Recognising and assessing respiratory distress}

Clinical indicators of respiratory failure include an increasing respiratory rate, decreasing oxygen levels, or increasing supplementary oxygen requirement. Patients may also describe chest tightness and/or an inability to breathe deeply, and may look and/or feel increasingly anxious. These symptoms, alongside psychological distress and fear, exacerbate breathlessness by further raising the respiratory rate and warrant prompt clinical review.
Oxygen levels are assessed by peripheral oxygen saturation ( $\mathrm{SpO} 2)$ and/or arterial or capillary oxygen partial pressure ( $\mathrm{PaO} 2$ or $\mathrm{PcO} 2)$. $\mathrm{SpO} 2$ is favoured during covid- $19^{12}$ because of its ease and speed of monitoring unless there is concern of hypercapnia. The normal range for $\mathrm{SpO} 2$ is 94-98\%, although clinicians have been advised to target $92-96 \%$ during the covid-19 pandemic to aid conservation of hospital oxygen supplies. Clinical trials have demonstrated that these lower oxygen target ranges are safe: they are sufficiently high to alleviate dyspnoea and maintain tissue oxygenation, while avoiding the potentially harmful effects of hyperoxia and conserving hospital oxygen supplies. ${ }^{13}$ The normal range for $\mathrm{PaO} 2$ is 12.6-14 $\mathrm{kPa} .{ }^{14}$ Key features of respiratory distress are summarised in the infographic. ${ }^{15}$

As noted above, breathlessness may not be as prevalent or severe as expected for a given level of hypoxia in covid-19. ${ }^{4}$ Therefore, extra vigilance is required, as decreasing $\mathrm{SpO} 2$ and an increased oxygen requirement may be the only markers of deterioration signalling the need to escalate treatment. 
thebmj visual summary Covid-19: Options for respiratory support

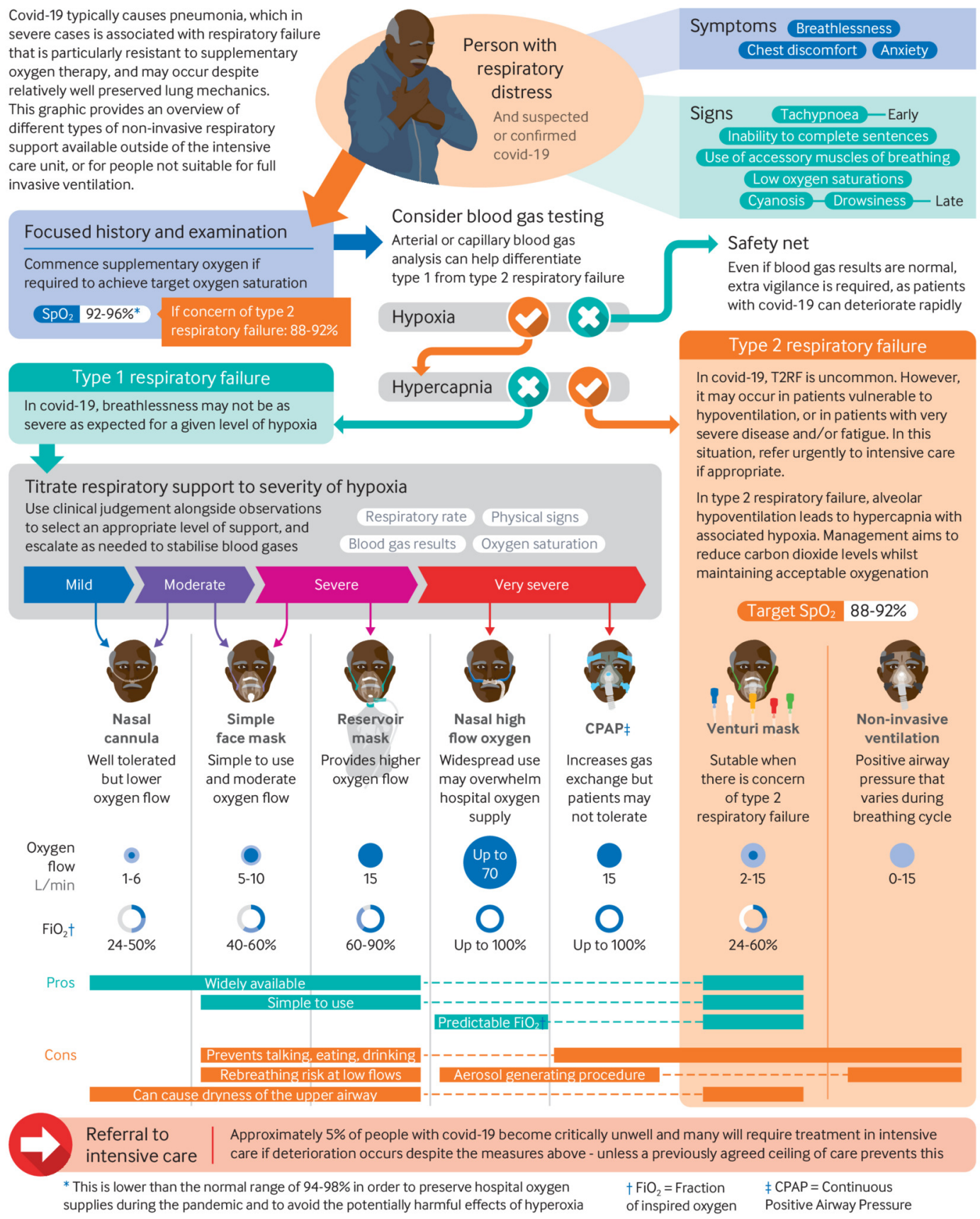

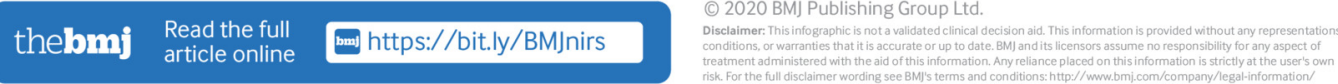

(C) 2020 BMJ Publishing Group Ltd

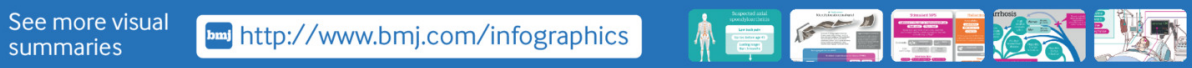

\section{Management of respiratory failure}

The tenets of managing respiratory failure are to maintain adequate oxygen levels, avoid hypercapnia, treat the underlying cause where possible (such as antibiotics for bacterial pneumonia), and reduce the risk of potential complications (for example, venothromboembolism prophylaxis), while optimising hydration, nutrition, and patient comfort (box 1). Additional management considerations in the covid-19 pandemic include an enhanced focus on infection prevention and control, appropriate ward allocation within the hospital based on illness severity and infection control requirements, prompt decisions regarding ceilings of care, and 
recruitment into research trials. ${ }^{16} 17$ Table 2 lists terminology used in non-invasive respiratory support.

\section{Box 1: Approach to assessing and managing respiratory failure}

- Focused history and examination alongside starting supplementary oxygen if required to achieve target peripheral oxygen saturation $(\mathrm{SpO} 2)$
- Start treatment for underlying cause if possible

- Escalate supplementary oxygen as required to maintain target $\mathrm{SpO}_{2}$ and consider arterial or capillary blood gas analysis to differentiate type 1 respiratory failure from type 2

- If required, commence non-invasive respiratory support (continuous positive airway pressure (CPAP) or non-invasive ventilation (NIV))

Table 2 | Terminology of non-invasive respiratory support

\begin{tabular}{|c|c|c|}
\hline Primary term & $\begin{array}{l}\text { Synonyms used in } \\
\text { intensive care }\end{array}$ & Meaning \\
\hline $\begin{array}{l}\text { Positive end expiratory pressure (PEEP) } \\
\text { or } \\
\text { Expiratory positive airway pressure } \\
\text { (EPAP) }\end{array}$ & e-PEEP, low PEEP, Plow & $\begin{array}{l}\text { This is the pressure set during expiration, the lowest pressure during the respiratory cycle. It is primarily used to splint open } \\
\text { additional alveolar units and therefore improve oxygenation }\end{array}$ \\
\hline $\begin{array}{l}\text { Continuous positive airway pressure } \\
\text { (CPAP) }\end{array}$ & e-PEEP, low PEEP, Plow & $\begin{array}{l}\text { Like PEEP and EPAP, this is also the pressure set during expiration. It is used to splint open the lower airway (improve } \\
\text { oxygenation) but is also the term for treatment when the aim is to splint open the upper airway, for example, when treating } \\
\text { obstructive sleep apnoea } \\
\text { Unlike PEEP and EPAP, this terminology would not be used when giving NIV (where the pressure delivered is variable, so the } \\
\text { term "continuous" becomes inappropriate) }\end{array}$ \\
\hline $\begin{array}{l}\text { Inspiratory positive airway pressure } \\
\text { (IPAP) }\end{array}$ & $\begin{array}{l}\text { Phigh, inspiratory pressure, } \\
\text { i-PEEP, high PEEP }\end{array}$ & , This is the pressure set during inspiration, the highest pressure in the lung during the respiratory cycle \\
\hline Pressure support (PS) & $\begin{array}{c}\text { Driving pressure }(\Delta P) \text {, } \\
\text { pressure assist }\end{array}$ & PS = IPAP-EPAP. This controls the amount of ventilation, as increasing the PS will increase the tidal volume in each breath \\
\hline Non-invasive ventilation (NIV) & BiPAP, bi level, NIPPV & $\begin{array}{l}\text { Positive airway pressure that varies during the breathing cycle, to provide not only an elevated baseline airway pressure (PEEP } \\
\text { or EPAP), but also an elevated inspiratory pressure (IPAP), which is triggered when the patient starts taking a breath in }\end{array}$ \\
\hline
\end{tabular}

\section{Case scenario (continued)}

You increase supplementary oxygen delivery to your patient by applying a facemask delivering $8 \mathrm{~L} / \mathrm{min}$ of oxygen. His $\mathrm{SpO}_{2}$ improves to $96 \%$ and respiratory rate falls to 18 breaths/min.

Later that day, his nurse alerts you that his respiratory rate has increased to 26 breaths/min, he is using accessory muscles of breathing, and his $\mathrm{SpO} 2$ is $90 \%$ despite switching to a reservoir mask delivering $15 \mathrm{~L} / \mathrm{min}$ oxygen. The patient is started on continuous positive airway pressure (CPAP), and the intensive care team are informed.

\section{Type 1 respiratory failure (T1RF)}

The aim of management in $\mathrm{T} 1 \mathrm{RF}$ is to improve oxygenation via two main interventions.

1. Increasing the fraction of inspired oxygen ( $\mathrm{FiO} 2$ )-The choice of delivery device (see infographic) is determined by the oxygen requirement and patient comfort: patients should receive the lowest FiO2 required to maintain target $\mathrm{SpO} 2$.

2. Applying positive end expiratory pressure (PEEP) to the airway during expiration can further improve oxygenation by splinting open the alveoli and smaller airways that may otherwise close during expiration in respiratory infection. This reduces deoxygenated blood flowing through areas of poorly ventilated lung (intrapulmonary shunting) and effectively increases the surface area available for gas exchange. ${ }^{18} 19$ PEEP may be indicated alongside increasing $\mathrm{FiO}_{2}$ when target oxygenation has not been achieved. The most effective means of achieving PEEP in non-intubated patients is with continuous positive airway pressure (CPAP), which is different from non-invasive ventilation (NIV) (see infographic). CPAP involves wearing a snug-fitting mask through which pressurised air is applied. It is most commonly used to splint open the upper airway in obstructive sleep apnoea; for T1RF, it splints open the lower airways in order to increase gas exchange.
Respiratory support will progress from the most simple, best tolerated devices using the least oxygen to achieve target $\mathrm{SpO}_{2}$-typically, in the sequence nasal cannula, oxygen mask, and then CPAP or high flow nasal oxygen. A venturi mask may be used instead of nasal cannula or oxygen mask in patients who are susceptible to T2RF (table 1), to deliver a precise FiO2.

CPAP is increasingly recommended when treating covid-19, with suggested pressure ranges of 8-14 $\mathrm{cm} \mathrm{H} 2 \mathrm{O},{ }^{12} 20$ although there are contraindications to CPAP (box 2). Another way to improve oxygenation that has been advocated for patients with covid-19 is "awake proning." ${ }^{21}$ Proning is an established therapy for refractory $\mathrm{T} 1 \mathrm{RF}$ in intubated patients that improves oxygenation by minimising ventilation/perfusion mismatch in the lung. ${ }^{22} 23$ Proning has been widely used in awake patients with covid-19, ${ }^{21} 2425$ although high quality evidence regarding its efficacy in awake patients is pending.

Box 2: Contraindications to continuous positive airway pressure (CPAP)

- Agitated or uncooperative patient

- Reduced conscious level with inability to protect airway

- Facial burns or trauma

- Persistent vomiting

- Unstable cardiorespiratory status or respiratory arrest

- Copious respiratory secretions

- Non-drained pneumothorax

For some patients, CPAP (with or without awake proning) may be used as a holding measure while awaiting intubation. The intensive care team should be involved in this situation. High flow nasal oxygen is a theoretical alternative to CPAP, combining increased FiO2 with up to $5 \mathrm{~cm} \mathrm{H} 2 \mathrm{O}$ PEEP, ${ }^{26}$ but NHS England has advised against its use when treating covid-19 because of lack of efficacy, high oxygen consumption, and risk of infectious spread. ${ }^{12}$ In some 
patients, CPAP is sufficient to support patients' breathing and avoid the risks of invasive ventilation altogether. ${ }^{20}$

\section{Type 2 respiratory failure (T2RF)}

In T2RF (table 1) alveolar hypoventilation leads to hypercapnia with associated hypoxia. Management aims to reduce carbon dioxide while maintaining acceptable oxygenation, with target a SpO2 of $88-92 \% .{ }^{14}$ Carbon dioxide is reduced by increasing minute ventilation, the product of respiratory rate and tidal volume $(\mathrm{MV}=\mathrm{RR}$ $\mathrm{x}$ VT). This is achieved by:

1. Increasing the respiratory rate-This is difficult to achieve in an awake, unwell patient who is already tachypnoeic. Beyond a certain level, further increases in respiratory rate do not clear more carbon dioxide, since breathing becomes inefficient due to "dead-space" ventilation of airways where no gas exchange occurs.

\section{Increasing the volume of air moved with each breath (tidal} volume)-This reduces alveolar carbon dioxide levels. As carbon dioxide readily diffuses from the pulmonary capillaries into the alveolar space, the blood $\mathrm{CO} 2$ level is closely affected by changes in alveolar ventilation. This is the basis for non-invasive ventilation (NIV), which delivers positive airway pressure that varies during the breathing cycle, providing an elevated baseline or end expiratory airway pressure (PEEP or EPAP) and a separate, elevated inspiratory pressure (IPAP) provided when the patient starts breathing in (table 2, infographic).

Pressure settings vary depending on the patient's underlying condition. ${ }^{27}$ For example, high pressure will be needed in COPD (such as IPAP $20 \mathrm{~cm} \mathrm{H} 2 \mathrm{O}$; EPAP 4 cm H2O) and obesity (such as IPAP $20 \mathrm{~cm} \mathrm{H2O}$; EPAP $8 \mathrm{~cm} \mathrm{H2O}$ ) because of airway resistance and poor chest wall compliance, respectively. In neuromuscular disease, however, respiratory system compliance is usually normal so lower pressures are required (such as IPAP 12; EPAP $4 \mathrm{~cm} \mathrm{H2O).} \mathrm{Increasing}$ PEEP/EPAP to improve oxygenation must be matched by an equal increase in IPAP to maintain the same effective tidal volume and carbon dioxide control.

T2RF is uncommon in covid-19. ${ }^{16}$ However, patients vulnerable to hypoventilation-including those with COPD or obesity (table 1) as well as patients with severe disease or fatigue-may be at higher risk of developing T2RF. For patients with T2RF due to severe covid-19 or fatigue, NIV should only be used as a bridge to urgent intubation, or as the ceiling of care.

\section{Other considerations}

When using CPAP or NIV in covid-19, a non-vented mask with a bacterial or viral filter between the patient and the expiratory port may reduce environmental contamination. ${ }^{12}$ While it is beyond the scope of this article to discuss the haematological abnormalities associated with covid-19, there is evidence that it induces a prothrombotic state that increases the risk of venous

thromboembolism. ${ }^{2829}$ Therefore, clinicians must have a high index of suspicion for pulmonary embolism that would worsen respiratory failure.

\section{Ceiling of care, intubation, and invasive ventilation}

The ceiling of care is the maximal level of care that is appropriate for a given patient, considering factors such as their (or their advocates') wishes, underlying comorbidities, and frailty. Guidance exists from professional bodies to support this decision making. ${ }^{30}$ Best practice is for individuals, their family members, and their general practitioner or secondary care team to discuss and jointly agree a ceiling of care before the patient becomes acutely unwell or is unable to express their wishes. All patients with covid-19 in hospital and many of those in the community should have a ceiling of care established at the earliest opportunity. ${ }^{30} 31$

Intubation and invasive ventilation are indicated when a patient suitable for full support deteriorates despite the measures above. For patients in whom invasive ventilation has been deemed inappropriate, CPAP or NIV could be used as the ceiling of care. Before commencing either, the ceiling of care should be determined.

\section{A patient's perspective}

A patient with severe covid-19 improved with CPAP, avoiding invasive ventilation.

During recovery, he provided insightful feedback. Earlier treatment with nasal cannula and then reservoir mask had been tolerable as he was able to communicate, eat, and drink. In contrast, CPAP was

"claustrophobic" and "suffocating." He was scared of vomiting and being unable to remove the mask, while "simple communication with staff became a task" which made him angry. Better explanation of the rationale behind treatment would have helped his tolerance.

\section{Education into practice}

- What is the difference between T1RF and T2RF, and how does this influence decisions regarding respiratory support?

- Do you know the difference between CPAP, EPAP, PEEP, and IPAP?

- Would you feel comfortable explaining CPAP or NIV to a patient or family member?

\section{How patients were involved in the creation of this article}

A patient recovering from covid-19 who was treated with different forms of non-invasive respiratory support during his admission to hospital was interviewed about the devices used, their application by staff and his experience of them.

\section{Sources and selection criteria}

This article is based upon personal practice, clinical experience, papers available via PubMed, and national guidelines and statements.

Competing interests: We have read and understood BMJ policy on declaration of interests and have no relevant interests to declare.

Patient consent not required (patient anonymised, dead, or hypothetical).

Provenance and peer review: Commissioned, based on an idea from the author; externally peer reviewed.

NHS Health Education England. Medical workforce planning and deployment to support surge service delivery: HEE support for NHS England and NHS Improvement. 15 April 2020. In: Coronavirus (COVID-19) overview. 2020. https://www.hee.nhs.uk/coronavirus-covid-19/coronavirus-covid-19-overview.

2 Wu Z, McGoogan JM. Characteristics of and important lessons from the coronavirus disease 2019 (COVID-19) outbreak in China: summary of a report of 72314 cases from the Chinese Center for Disease Control and Prevention. JAMA 2020.

doi: 10.1001/jama.2020.2648. pmid: 32091533

3 Yang $X, Y u$ Y, Xu J, etal. Clinical course and outcomes of critically ill patients with SARS-CoV-2 pneumonia in Wuhan, China: a single-centred, retrospective, observational study. Lancet Respir Med 2020;8:475-81. doi: 10.1016/S2213-2600(20)30079-5. pmid: 32105632

4 Guan WJ, Ni ZY, Hu Y, etalChina Medical Treatment Expert Group for Covid-19. Clinical characteristics of coronavirus disease 2019 in China. N Engl / Med 2020;382:1708-20. doi: 10.1056/NEJMoa2002032. pmid: 32109013

5 Murthy S, Gomersall CD, Fowler RA. Care for critically ill patients with COVID-19. JAMA 2020. doi: 10.1001/jama.2020.3633. pmid: 32159735

6 Grasselli G, Zangrillo A, Zanella A, etalCOVID-19 Lombardy ICU Network. Baseline characteristics and outcomes of 1591 patients infected with SARS-CoV-2 admitted to ICUs of the Lombardy region, Italy. JAMA 2020. doi: 10.1001/jama.2020.5394. pmid: 32250385

Marini JJ, Gattinoni L. Management of COVID-19 respiratory distress. JAMA 2020. doi: 10.1001/jama.2020.6825. pmid: 32329799 
8 Archer SL, Sharp WW, Weir EK. Differentiating COVID-19 pneumonia from acute respiratory distress syndrome (ARDS) and high altitude pulmonary edema (HAPE): therapeutic implications. Circulation 2020. doi: 10.1161/CIRCULATIONAHA.120.047915. pmid: 32369390

9 Ackermann M, Verleden SE, Kuehnel M, etal. Pulmonary vascular endothelialitis, thrombosis, and angiogenesis in Covid-19. N Engl/ Med 2020. doi: 10.1056/NEJMoa2015432. pmid: 32437596

10 Lang M, Som A, Mendoza DP, etal. Hypoxaemia related to COVID-19: vascular and perfusion abnormalities on dual-energy CT. Lancet Infect Dis 2020. doi: 10.1016/S1473-3099(20)30367-4. pmid: 32359410

11 Wilcox SR. Management of respiratory failure due to covid-19. BMJ2020;369:m1786. doi: 10.1136/bmj.m1786 pmid: 32366375

12 NHS England. Specialty guides for patient management during the coronavirus pandemic. Guidance for the role and use of non-invasive respiratory support in adult patients with COVID-19 (confirmed or suspected). 2020. https://www.england.nhs.uk/coronavirus/wp-content/up-

loads/sites/52/2020/03/specialty-guide-NIV-respiratory-support-and-coronavirus-v3.pdf.

13 NHS England. Specialty guides for patient management during the coronavirus pandemic. Clinical guide for the optimal use of oxygen therapy during the coronavirus pandemic. 2020. https://www.england.nhs.uk/coronavirus/wp-content/uploads/sites/52/2020/04/C0256-specialtyguide-oxygen-therapy-and-coronavirus-9-april-2020.pdf.

14 O'Driscoll BR, Howard LS, Earis J, Mak VBritish Thoracic Society Emergency Oxygen Guideline GroupBTS Emergency Oxygen Guideline Development Group. BTS guideline for oxygen use in adults in healthcare and emergency settings. Thorax 2017;72(Suppl 1):i1-90. doi: 10.1136/thoraxinl-2016-209729 pmid: 28507176

15 Stratton SJ. Acute respiratory failure. BMJ Best Practice. 2020. https://bestpractice.bmj.com/topics/en-gb/853.

16 Bennett J, Munavvar M, Walker P, Phillips G. Respiratory advice for the non-respiratory physician in the time of COVID-19. Clin Med (Lond) 2020. doi: 10.7861/clinmed.2020-0188. pmid: 32366580

17 Beeching N, Fletcher T, Fowler R. Coronavirus disease 2019 (COVID-19). BMJ Best Practice. 2020 https://bestpractice.bmj.com/topics/en-gb/3000168.

18 Smith RA. Physiologic PEEP. Respir Care 1988:33:620.

19 Oliven A, Taitelman U, Zveibil F, Bursztein S. Effect of positive end-expiratory pressure on intrapulmonary shunt at different levels of fractional inspired oxygen. Thorax 1980;35:181-5. do: 10.1136/thx.35.3.181 pmid: 6770485

20 Oranger M, Gonzalez-Bermejo J, Dacosta-Noble P, etal. Continuous positive airway pressure to avoid intubation in SARS-CoV-2 pneumonia: a two-period retrospective case-control study. Eur Respir / 2020. doi: 10.1183/13993003.01692-2020. pmid: 32430410

21 Bamford P, Bentley A, Dean J, Whitmore D, Wilson-Baig N. ICS guidance for prone positioning of the conscious COVID patient 2020. Intensive Care Society, 2020. https://emcrit.org/wp-content/uploads/2020/04/2020-04-12-Guidance-for-conscious-proning.pdf.

22 Ranieri VM, Rubenfeld GD, Thompson BT, etalARDS Definition Task Force. Acute respiratory distress syndrome: the Berlin Definition. JAMA 2012;307:2526-33. doi: 10.1001/jama.2012.5669. pmid: 22797452

23 Guérin C, Reignier J, Richard JC, etalPROSEVA Study Group. Prone positioning in severe acute respiratory distress syndrome. N Engl J Med 2013;368:2159-68. doi: 10.1056/NEJMoa1214103 pmid: 23688302

24 Caputo ND, Strayer RJ, Levitan R. Early self-proning in awake, non-intubated patients in the emergency department: a single ED's experience during the COVID-19 pandemic. Acad Emerg Med 2020;27:375-8. doi: 10.1111/acem.13994 pmid: 32320506

25 McNicholas B, Cosgrave D, Giacomini C, Brennan A, Laffey JG. Prone positioning in COVID-19 acute respiratory failure: just do it?Br J Anaesth 2020. doi: 10.1016/j.bja.2020.06.003.

26 Nishimura M. High-flow nasal cannula oxygen therapy in adults: physiological benefits, indication, clinical benefits, and adverse effects. Respir Care 2016;61:529-41. doi: 10.4187/respcare.04577 pmid: 27016353

27 Davidson AC, Banham S, Elliott M, etalBTS Standards of Care Committee Member, British Thoracic Society/Intensive Care Society Acute Hypercapnic Respiratory Failure Guideline Development Group, On behalf of the British Thoracic Society Standards of Care Committee. BTS/ICS guideline for the ventilatory management of acute hypercapnic respiratory failure in adults. Thorax 2016;71(Suppl 2):ii1-35. doi: 10.1136/thoraxjnl-2015-208209 pmid: 26976648

28 Helms J, Tacquard C, Severac F, etalCRICS TRIGGERSEP Group (Clinical Research in Intensive Care and Sepsis Trial Group for Global Evaluation and Research in Sepsis). High risk of thrombosis in patients with severe SARS-CoV-2 infection: a multicenter prospective cohort study. Intensive Care Med 2020;46:1089-98. doi: 10.1007/s00134-020-06062-x. pmid: 32367170

29 BTS Guidance on venous thromboembolic disease in patients with COVID-19. 2020. At: https://www.brit-thoracic.org.uk/about-us/covid-19-information-for-the-respiratory-community/.

30 National Institute for Health and Care Excellence. COVID-19 rapid guideline: critical care in adults (NICE guideline NG159). 2020. https://www.nice.org.uk/guidance/ng159.

31 Resuscitation Council (UK). Resuscitation Council UK statement on COVID-19 in relation to CPR and resuscitation in acute hospital settings. 2020. https://www.resus.org.uk/media/statements/resuscitation-council-uk-statements-on-covid-19-coronavirus-cpr-and-resuscitation/covid-healthcare/.

This article is made freely available for use in accordance with BMJ's website terms and conditions for the duration of the covid-19 pandemic or until otherwise determined by BMJ. You may use, download and print the article for any lawful, non-commercial purpose (including text and data mining) provided that all copyright notices and trade marks are retained. 